michie_aam_nhs to Ig.docx

\title{
From NHS to local government: perceptions of public health transition in England
}

\section{Abstract \\ Objectives}

In England in 2013, responsibility for some public health (PH) functions transferred from the National Health Service (NHS) to local government. This moved PH from a health-focussed into a broader and more politically-oriented context. This paper reports on the perceptions of those involved in this transition about how the $\mathrm{PH}$ function was changing as it transited to local government.

\section{Study design}

Cross-sectional interview study.

\section{Methods}

Semi-structured interviews with 31 local government councillors, directors and deputy directors of $\mathrm{PH}, \mathrm{PH}$ team members and members of clinical commissioning groups (CCGs). Interviews and data analysis were informed by a theoretical framework, COM-B and an inductive and deductive approach was taken to identify relevant themes.

\section{Results}

There was a mixed picture of perceived gains and losses for PH. The transition from NHS to local government was seen by some as a 'homecoming', providing the opportunity for PH to have further reach through influence and collaboration with departments like housing, transport and planning. The opportunity to promote evidence-based practice across local government was also seen as a positive aspect of the transition. 
However, professional roles of $\mathrm{PH}$ and individual $\mathrm{PH}$ practitioners were perceived to have less influence and autonomy than in the NHS, with some uncertainty about roles within local government. PH practitioners perceived the need to develop other skills to fulfil their roles in local government. Shorter timescales for action and pressure for faster responses were reported to be the reason for less emphasis on using PH evidence to inform policy and decision-making than hitherto in the NHS.

\section{Conclusion}

This study illustrates a variety of consequences of transitioning from NHS to local government. There were perceived benefits afforded by proximity to related local government departments but at the costs of reduction in status for PH practitioners and working to a timescale which in some cases reduced drawing on scientific evidence.

\section{Keywords}

Evidence-based practice, guidelines, local government, reorganisation. 
michie_aam_nhs to Ig.docx

\section{Introduction}

Local government was the home of many public health $(\mathrm{PH})$ services until 1974 when responsibility for these moved to the National Health Service (NHS). One advantage of this was that with the rise of evidence-based medicine, the NHS, including PH, became familiar with using evidence-based guidelines(1). On 1 April 2013, in accordance with the Health and Social Care Act 2012, responsibility for delivering most PH services transferred to local government. The rationale for this transition was that local government was better placed to meet local health needs by co-ordinating departments allied to $\mathrm{PH}$ such as education, transport and housing and in doing so address social influences on health(2) and to tackle local health inequalities(3).

Whilst placing PH services in local government has the potential to deliver more locally relevant services, the context is different from the NHS. Local authorities are democratically accountable political organisations - the NHS is not. Local authorities have a long history of using evidence from engineering, planning, building construction and environmental health, for example, but not of evidence-based health related guidelines. While engineering, planning and the other areas have clear methods for collecting and interpreting evidence and data, they are for the most part quite distinct from the principles of evidence-based medicine and $\mathrm{PH}(4)$.

The context of practising PH in England since 2013 has been dominated by a significant reduction in funding which has had major implications for (i) the determination of $\mathrm{PH}$ priorities, (ii) the methods by which these priorities are met; (iii) how evidence-based guidelines for $\mathrm{PH}$ are used; and (iv) what constitutes admissible evidence to inform a $\mathrm{PH}$ strategy - which ours and other previous research suggests will be perceived very variably(57). At the same time as funds have been cut, the rhetoric about the importance of evidence has accumulated(8). International efforts to promote evidence-based $\mathrm{PH}$ policy such as that by the WHO European Region(9) have not been translated into practice in England. The government 
michie_aam_nhs to lg.docx

white paper 'Healthy lives, Healthy people'(10) which proposed the shifting of the PH function to Local Government, contained recommendations about interventions but they were not ones where the evidence was strongest(11). This is perhaps not surprising as it has been observed consistently that at local level forms of information like the views of the community, have much more traction than research evidence(5). Also lack of timely access to clear, relevant research evidence has been identified as the main barrier to the use of research evidence(12). Threats to status and clarity of role in those transitioning in reorganisations have been identified as a problem in service reconfigurations(13). Previous research on the impact of the transition from NHS to local government on public health specialists has reported that it took a long period of time for public health teams to adjust to operating in the context of local government. Whilst those working in public health teams have felt more able to influence local government priorities, they often perceived this influence to be limited. Given the potential threat to the effective delivery of $\mathrm{PH}$ that these issues present, the current study set out to investigate the impact of transferring PH responsibility from NHS to local government by asking what is the impact of this transfer of responsibility on i) the $\mathrm{PH}$ practitioner role (defined as officers working in $\mathrm{PH}$ teams including directors and assistant/deputy directors of $\mathrm{PH}, \mathrm{PH}$ specialists, nurse consultants in $\mathrm{PH}$, health Improvement managers and officers) and ii) the use of evidence, including guidelines, in decision-making?

\section{Methods}

\section{Sample}

Thirty-one interviews were conducted in four local authorities with councillors, local government officers (directors and deputy directors of $\mathrm{PH}$, officers working directly on $\mathrm{PH}$ issues and officers based in other departments whose work related to $\mathrm{PH}$ ) and members of clinical commissioning groups. Table 1 summarises interviewees' roles. 
Table 1 here

Table 2 summarises interviewees' current role, their role prior to 2013 (whether from an NHS or local government background), and the wave of analysis of each interview. Of the 21 officers, only a third were working in local government prior to 2013.

Table 2 here

\section{Procedure}

Potential case study sites were identified through: i) contacts known to research team members; ii) an article about the project in the UK's Association of Directors of PH newsletter; iii) attendees at a NICE local government conference. Case study sites were selected based on geography and urbanisation with the intention of reflecting different levels of deprivation and to encompass both common experiences across Local Government and experiences particular to each site. The final four sites were: a unitary authority in the north of England; inner and outer London boroughs and a two-tier authority in South West England with rural areas. Interviews were conducted face-to-face, audio-recorded and transcribed and anonymised.

\section{Interview schedule}

The interview schedule was structured according to the COM-B model(14) to cover topics relevant to the research questions. COM-B is a simple, comprehensive model summarising all potential influences on behaviour (Capability, Opportunity and Motivation). Full interview schedules are provided in Supplementary File 1. The schedule was refined following pilot interviews not included in the project. 
michie_aam_nhs to lg.docx

\section{Data analysis}

Analysis was conducted in three waves of 11,10 and 10 transcripts. This allowed the development of an analytical framework identifying themes emerging from the data and a process of triangulation within the data, suggesting which findings could be generalised across sites. Examination of the third wave of transcripts confirmed saturation. We have previously published a full description of data analysis(15).

\section{Results}

Five key themes were identified: i) status of PH practitioners; ii) local government priorities; iii) timescales for change; iv) reach of $\mathrm{PH}$ within local government; and v) disease focus of PH.

\section{Change in status and skills for PH practitioners}

\section{PH practitioners have lower status than in the NHS}

Those previously working in the NHS perceived themselves to have lower status working in local government due to the different managerial structure.

The way you work your way up in local government is by the number of people you manage and the amount of money you control. On that basis consultants in local government are quite low down in the pecking order. (Site 2, Off 1)

However, this was not echoed by elected officials who viewed the roles as equal in status due to the different strengths of the roles.

I see them as the experts, and I'm here to support them. So they, in many ways, they lead us. And then, politically, we lead them. So, it's really a, it's a two way street. (Site 1, Cllr 1). 
michie_aam_nhs to lg.docx

\section{Uncertainty about $\mathrm{PH}$ practitioner role}

There was a perception amongst those who had moved from the NHS that their roles were not understood by new colleagues.

I'm not sure people understand. ... whereas I think, when we were in healthcare, we'd been established a long time, it was clear what our role was. (Site 2, Off 4)

This was echoed in terms of the extent to which PH practitioners perceived themselves to be actively sought after for input by allied departments.

I think they forget about PH but when we do meet with them they do seem to sort of take our advice seriously.... But it's difficult to get through those doors. (Site 2, Off 7)

\section{Need to develop skills in commissioning and other areas of $\mathrm{PH}$}

PH practitioners acknowledged the need to develop new skills such as commissioning to operate effectively in the new context.

Our previous role wasn't commissioning at all ... we just provided the evidence base ... so it's been a bit of a steep learning curve... we've had to learn what is commissioning and how do we build that competency. (Site 1, Off 3)

They also acknowledged their role in developing elected members' understanding of the function of $\mathrm{PH}$ in local government.

They [elected members] freely admit there are many gaps in their understanding. They're keen to learn and therefore we're now embarking on quite a significant developmental awareness raising. Teaching people what it is they should be scrutinising us about. (Site3, Off 1) 
michie_aam_nhs to Ig.docx

\section{Influences on deciding PH priorities}

Participants suggested a number of influences on how PH priorities are decided. These included costs saving to local government rather than the NHS.

... it's no use telling a Council that you're going to save X thousand pounds in NHS costs because they'll go, that's lovely but that's not really what our priority is. (Site 1, Off 2)

NICE looks at cost effectiveness, but ... it's cost effective to the NHS, the Councils aren't bothered about that. ... If I've got to make 1100 million savings to the Council and all I can produce from the NICE guidance is ... we're going to save loads of money, in hospital admissions, I'd like to say that they're all interested, but they're really not (Site 2, Off 3)

They also included the need to fit with strategic priorities.

...you have to keep on linking stuff to the core strategic priorities, which keep on narrowing because funding keeps on narrowing and it keeps on getting ever tighter. ... So, trying to make sure evidence plays a bigger part in decision making, I don't know how one does that. (Site 4, Off 3)

Participants also suggested factors that did not influence priority decision making such as an absence of evidence for cost-effectiveness of interventions.

There's an awful lot of evidence out there about what works, what's effective, .... There's less about is it cost effective... You might know that a particular intervention or a medicine is cost effective, but what's cost effective on a programme level? (Site 1, Off 2)

\section{Shorter timescales to assess evidence and implement change}


michie_aam_nhs to lg.docx

\section{Fast turnaround}

There was the perception from those working previously in the NHS that timescales to assess evidence were now much shorter and lagged behind the political and financial priorities of the moment.

... they would like an answer quite quickly. And sometimes, the answer, if you were going to give a sort of comprehensive and evidence-based answer, you can't do it overnight, necessarily. (Site 2, Off 4)

So, the exec member might say, what's going on about this issue? ... They'll ask a question and they expect you to respond and turn that over quite quickly. (Site 1, Off 3)

\section{Looking less for evidence}

The pressure to implement change quickly affected the amount of time that was devoted to looking at evidence.

And, it's not always a quick process, to get to the quality answer, the most comprehensive answer... So, I think that's a good example of where, there's a tension. (Site 2, Off 4)

Most decision making in the Council, is based on historical decisions, or... innovation is not evidenced at all. And, all the signs are, it's getting worse than that, and we're actively being discouraged to look at the evidence, and to just come up with something in the next five minutes and go with it. (Site 2, Off 3)

\section{Focus on short-term goals}

Participants perceived there to be a focus on short-term goals and effecting change quickly rather than focussing on long-term strategies. 
michie_aam_nhs to Ig.docx

We quite often go for the things that we can see happen within either an electoral term ... and we're less inclined to take that leap ... and say well actually, if we invest a million pounds in making sure people have nice homes, they are more likely to be healthy, or their kids are more likely to be healthy forty years down the line. (Site 2, Off 6)

Whilst practitioners acknowledged that PH should be accountable; due to the short-term focus, they perceived themselves to be unreasonably held to account over outcomes that would take a long time to realise.

So, the local authorities are effectively saying to $\mathrm{PH}, \ldots$ if you want to keep that structure and that level of resource you have to demonstrate your added benefit. Well actually that's quite hard to do for PH because it is slow going. (Site 2, Off 5)

\section{PH has a further reach in local government}

\section{Collaboration with allied departments}

Participants from all backgrounds discussed the benefits of $\mathrm{PH}$ working with other local government departments and being able to deliver PH services better.

Local authority has got the infrastructure or access to an infrastructure that the CCG doesn't have. ... they have so many communications that they can reach far more people than PH ever could have done in health. (Site 2, Off 5)

I think the key issue for us has been that close collaboration and day to day working means that the health of our public is everybody's concern, and it's just intertwined with everything that we do. (Site 1, Off 5)

\section{Local government identifying as $\mathrm{PH}$ organisation}


michie_aam_nhs to Ig.docx

Some participants suggested that local government identified as a $\mathrm{PH}$ organisation because that was where PH existed prior to 1974.

They [local authorities] were initially conceived, ... as $P H$ organisations and not everyone might see themselves as $\mathrm{PH}$ people but actually, a lot of people already do. (Site 1, Off 2)

The impact of council decision making in all arenas on PH was noted.

Everything the county does affects people in terms of transport, infrastructure, buses, bus passes, everything else but it all comes down to PH. PH is affected by everything that the county council does in some way or another. So PH coming to the county is the best thing. (Site 3, Cllr 2)

\section{Uneasy fit between disease-focussed PH evidence base and the community focus of local government}

There was a perception among some that NICE guidance, for example, is disease-focussed which does not fit with how local government defines problems and was therefore of limited use.

This is NICE guidance, this is what we have to do from a clinical point of view, which I think is very different to some of the PH areas. (Site 2, Off 6)

It is important to note though that this perception notwithstanding, NICE PH and social care guidelines are not purely disease-focussed(16). However, the fact that it was misperceived by some respondents remains a barrier to the implementation of guidelines.

\section{Discussion}

Factors affecting the $\mathrm{PH}$ practitioner role included a loss of status relative to their erstwhile standing in the NHS. However, practitioners recognised the potential for PH to be delivered 
michie_aam_nhs to lg.docx

more effectively by having purchase in local government. Factors affecting the use of evidence were the lead times in which decisions on $\mathrm{PH}$ strategies were made; practitioners previously working in the NHS reported faster turnaround times in local government which meant less time to review evidence. The perceived focus on making immediate impact means a focus on short-term goals rather than a long-term $\mathrm{PH}$ strategy. The perception that there was a lack of cost-effectiveness evidence for PH interventions was noted as a barrier to evidence informing PH priorities.

The themes of loss of status of $\mathrm{PH}$ practitioners echoes previous research in the UK reporting how Directors of PH shifted from being key decision-makers in the Primary Care Trusts to 'expert advisors to elected members' in local government(17), where their professional judgement is sometimes overruled or perceived to potentially count for less than the local knowledge of councillors(7). However, responses to the UK Association of Directors of PH annual survey suggest some Directors have increasingly positive perceptions of the influence they have in local government(18). Our finding that a lack of time to identify evidence to inform decision-making aligns with other studies reporting that availability of, and timely access to, evidence is a key factor in the extent to which evidence is used(11). PH practitioners' acknowledgement of their need to develop service commissioning skills complements previous research reporting the perceptions of local government staff of incoming NHS PH practitioners' absence of experience in commissioning(17). Whilst we have reported elsewhere that participants acknowledged the different conceptualisations of evidence in local government(15); what did not come out as strongly as noted in other research, was practitioners embracing new ways of communicating evidence in local government(19).

Our findings suggest two research implications: i) those producing evidence need to work in partnership with those making decisions about PH locally so that evidence can be accessed within the timescales they work to; and ii) researchers should work more closely with local 
michie_aam_nhs to Ig.docx

government PH teams to define research questions through the lens of the local government and their priorities and imperatives, taking into account the context of the significant loss of resources local authorities are dealing with. These implications are supported elsewhere in the literature reporting that partnerships between policy makers and researchers are a key facilitator to using evidence to inform policy(12).

The implications for practice are: i) to increase PH teams' familiarity with evidence resources, so they can access it quickly; this can be achieved through internal training and peer sharing, and developing accessible and useable resources; ii) for PH to work in collaboration with other local government departments and through the formation of local strategic partnerships to develop PH strategies which target, e.g. individual, community and organisational levels as recommended in NICE guidance on behaviour change(20). An example of such cross-sectoral working would be encouraging children to be more physically active which might be achieved through the PH team combining with planning to deliver attractive community places for children to be physically active. PH practitioners working with other departments might also have a positive spill-over effect of addressing the issue of their perceived lower status in local government compared with the NHS as their expertise is drawn on and their role more widely recognised. Although local government generally has a commitment to a whole systems approach to $\mathrm{PH}(21)$, translating that commitment into practice is challenging and often not achieved.

A limitation of this study is the small sample size which may limit the extent to which findings can be extrapolated. Although our sampling strategy ensured the inclusion of relevant groups within the PH teams and officers in other local government teams, these were not uniform across the four case study sites. For example, case study site one included four officers from other local government departments, but we were unable to recruit any in case study sites three and four. A second limitation is that aside from the six councillors interviewed, six participants 
michie_aam_nhs to lg.docx

were from departments other than $\mathrm{PH}$, so views largely reflected the perspective from within local government $\mathrm{PH}$ teams rather than from departments allied to $\mathrm{PH}$. A third limitation is the sampling strategy which focussed only geography and urbanisation. Factors such as political constitution and level of deprivation (rather than geography as a proxy for deprivation as we have done in this study) may influence experience transitioning from NHS to local government. As reported elsewhere in the literature(17), the perceptions of those involved in the transition of PH services from NHS to local government were a mixture of benefits and drawbacks. Those transitioning from the NHS sometimes perceived themselves to have lower status in local government. However, this may be ameliorated by an identified benefit of the proximity facilitating closer working with other relevant departments. This may raise the profile of the $\mathrm{PH}$ teams and achieve change at multiple levels that is characteristic of more effective interventions. An increase in emphasis on robust development and evaluation of $\mathrm{PH}$ interventions and making evidence accessible according to local government timescales may address the issue of evidence-based recommendations currently being used sub-optimally due to time pressure.

\section{Acknowledgements}

We would like to acknowledge colleagues in local government for their participation in this study. The views expressed in the paper those are of the authors and not of NICE. We also acknowledge the ESRC which funded the project, grant number ES/L006995/1. 


\section{References}

1. Kelly MP. The need for a rationalist turn in evidence-based medicine. Journal of evaluation in clinical practice. 2018;24(5):1158-65.

2. Marmot M. Fair society, healthy lives : the Marmot Review : strategic review of health inequalities in England post-2010.; 2010.

3. Health Do. Public Health in Local Government.; 2011.

4. Fischer AJ, Threlfall A, Meah S, Cookson R, Rutter H, Kelly MP. The appraisal of public health interventions: an overview. Journal of public health (Oxford, England). 2013;35(4):488-94.

5. Armstrong R, Waters E, Moore L, Dobbins M, Pettman T, Burns C, et al. Understanding evidence: a statewide survey to explore evidence-informed public health decision-making in a local government setting. Implementation science : IS. 2014;9:188-.

6. Atkins L, Smith JA, Kelly MP, Michie S. The process of developing evidence-based guidance in medicine and public health: a qualitative study of views from the inside. Implementation Science. 2013;8(1):101.

7. Marks L, Hunter DJ, Scalabrini S, Gray J, McCafferty S, Payne N, et al. The return of public health to local government in England: changing the parameters of the public health prioritization debate? Public health. 2015;129(9):1194-203.

8. Lorenc T, Tyner EF, Petticrew M, Duffy S, Martineau FP, Phillips G, et al. Cultures of evidence across policy sectors: systematic review of qualitative evidence. European journal of public health. 2014;24(6):1041-7.

9. Nguyen T, Zicker F, Kuchenmueller T. Action plan to strengthen the use of evidence, information and research for policy-making in the WHO European Region 2016.

10. Care DoHaS. Healthy Lives, Healthy People: our strategy for public health in England: White Paper. In: Care DoHaS, editor.: TSO (The Stationery Office); 2010.

11. Katikireddi S, Higgins M, Bond L, Bonell C, Macintyre S. How evidence based is English public health policy? BMJ. 2011;343.

12. Oliver K, Innvar S, Lorenc T, Woodman J, Thomas J. A systematic review of barriers to and facilitators of the use of evidence by policymakers. BMC Health Services Research. 2014;14(1):2.

13. Taylor C, Shewbridge A, Harris J, Green JS. Benefits of multidisciplinary teamwork in the management of breast cancer. Breast cancer (Dove Medical Press). 2013;5:79-85.

14. Michie S, van Stralen MM, West R. The behaviour change wheel: A new method for characterising and designing behaviour change interventions. Implementation Science. 2011;6(1):42.

15. Atkins L, Kelly MP, Littleford C, Leng G, Michie S. Reversing the pipeline? Implementing public health evidence-based guidance in english local government. Implementation Science. 2017;12(1):63.

16. Kelly M, Morgan A, Ellis S, Younger T, Huntley J, Swann C. Evidence based public health: A review of the experience of the National Institute of Health and Clinical Excellence (NICE) of developing public health guidance in England. Social science \& medicine (1982). 2010;71(6):1056-62.

17. Gadsby EW, Peckham S, Coleman A, Bramwell D, Perkins N, Jenkins LM. Commissioning for health improvement following the 2012 health and social care reforms in England: what has changed? BMC Public Health. 2017;17(1):211.

18. Health AoDoP. ADPH English Public Health System Survey.; 2015. 
19. Willmott M, Womack J, Hollingworth W, Campbell R. Making the case for investment in public health: experiences of Directors of Public Health in English local government. Journal of public health (Oxford, England). 2016;38(2):237-42.

20. Excellence NIfHaC. Behaviour Change: individual approaches. [NICE Public Health Guidance 49]. London; 2014.

21. Gorsky M, Lock K, Hogarth S. Public health and English local government: historical perspectives on the impact of 'returning home'. Journal of public health (Oxford, England). 2014;36(4):546-51. 
michie_aam_nhs to lg.docx

Table 1. Participant role in each local government site

\begin{tabular}{|l|c|c|c|c|}
\hline Role & Site 1 & Site 2 & Site 3 & Site 4 \\
\hline Director of PH & 1 & 1 & 1 & 1 \\
PH team & 2 & 2 & 2 & 3 \\
Clinical Commissioning group & 1 & 1 & 2 & 0 \\
Other local government department & 4 & 2 & 0 & 0 \\
District council & 0 & 0 & 2 & 0 \\
Councillor & 2 & 1 & 2 & 1 \\
\hline Total & $\mathbf{1 0}$ & $\mathbf{7}$ & $\mathbf{9}$ & $\mathbf{5}$ \\
\hline
\end{tabular}

Table 2. Participant current and previous role

\begin{tabular}{|c|c|c|c|}
\hline $\begin{array}{l}\text { Participant } \\
\text { ID }\end{array}$ & Role & Pre 2013 role & Wave \\
\hline 1 Off 1 & Director of PH & Other health & 2 \\
\hline 1 Off 2 & PH team & NHS & 2 \\
\hline 1 Off 3 & $\mathrm{PH}$ team & NHS & 3 \\
\hline 1 Off 4 & Clinical commissioning group & - & 3 \\
\hline 1 Off 5 & Other local government department & Local government & 2 \\
\hline 1 Off 6 & Other local government department & Local government & 3 \\
\hline 1 Off 7 & Other local government department & Local government & 3 \\
\hline 1 Off 8 & Other local government department & Local government & 3 \\
\hline 1 Cllr 1 & Councillor & - & 2 \\
\hline 1 Cllr 2 & Councillor & - & 2 \\
\hline 2 Off 1 & Director of PH & NHS & 1 \\
\hline 2 Off 3 & PH team & NHS & 3 \\
\hline 2 Off 4 & PH team & NHS & 1 \\
\hline 2 Off 5 & Clinical commissioning group & - & 2 \\
\hline 2 Off 6 & Other local government department & Local government & 2 \\
\hline 2 Off 7 & Other local government department & NHS & 3 \\
\hline
\end{tabular}


michie_aam_nhs to Ig.docx

\begin{tabular}{|c|c|c|c|}
\hline 2 Cllr 2 & Councillor & - & 1 \\
\hline 3 Off 1 & Director of PH & Other & 1 \\
\hline 3 Off 2 & PH team & NHS & 1 \\
\hline 3 Off 3 & PH team & NHS & 1 \\
\hline 3 Off 4 & District council & Other & 2 \\
\hline 3 Off 5 & District council & Local government & 3 \\
\hline 3 Off 6 & Clinical commissioning group & - & 2 \\
\hline 3 Off 7 & Clinical commissioning group & - & 3 \\
\hline 3 Cllr 1 & Councillor & - & 3 \\
\hline 3 Cllr 2 & Councillor & - & 2 \\
\hline 4 Off 1 & Director of PH & Other & 1 \\
\hline 4 Off 2 & PH team & Local government & 1 \\
\hline 4 Off 3 & $\mathrm{PH}$ team & NHS & 1 \\
\hline 4 Off 4 & PH team & Other health & 1 \\
\hline 4 Cllr 1 & Councillor & - & 1 \\
\hline
\end{tabular}

